\title{
Induction of Th1/mmune responses following laser ablation in a murine model of colorectal liver metastases
}

\author{
Wen Xu Lin ${ }^{\dagger}$, Theodora Fifis ${ }^{*}$, Caterina Malcontenti-Wilson, Mehrdad Nikfarjam, Vijayaragavan Muralidharan, \\ Linh Nguyen and Christopher Christophi
}

\begin{abstract}
Background: Preliminary experimental studies have suggested that the in situ destruction of tumor tissue by local laser ablation (LA) may also stimulate host immunity against cancer. We investigated local and systemic induction of immune responses after laser ablation in the setting of residual tumor.

Methods: A murine colorectal cancer (CRC) liver metastasis model was used. Selected tumors of liver CRC bearing mice and livers of mice without tumor induction were treated with LA. Liver and tumor tissues from the ablation sites and from distant sites were collected at various time points following LA and changes in CD3+ T cells and Kupffer cells (F4/80 marker) infiltration and the expression of interferon gamma (IFN $\gamma$ ) were investigated by immunohistochemistry and ELISpot. Base line levels of CD3+ T cells and Kupffer cells were established in untreated mice.

Results: The presence of tumor induced significant accumulation of CD3+ T cells and Kupffer cells at the tumorhost interface, within the tumor vascular lakes and increased their baseline concentration within the liver parenchyma. LA of the liver induced accumulation of CD3+ T-cells and Kupffer cells at the site of injury and systemic induction of immune responses as discerned by the presence of IFNy secreting splenocytes. LA of liver tumors induced significant increase of CD3+ T-cells at site of injury, within normal liver parenchyma, and the tumor-host interface of both ablated and distant tumors. In contrast Kupffer cells only accumulated in ablated tumors and the liver parenchyma but not in distant tumors. IFN $\gamma$ expression increased significantly in ablated tumors and showed an increasing trend in distant tumors.
\end{abstract}

Conclusion: Laser ablation in addition to local tumor destruction induces local and systemic Th1 type immune responses which may play a significant role in inhibiting tumor recurrence from residual micrometastases or circulating tumor cells.

\section{Background}

Colorectal cancer (CRC) is the most common solid organ cancer across both genders and the third most common cause of cancer related deaths [1]. More than $50 \%$ of patients with CRC develop liver metastases (CRCLM) which is the leading cause of death in this population. Surgical resection is the only potential curative option. The spatial distribution of metastases,

\footnotetext{
*Correspondence: tfifis@unimelb.edu.au

+ Contributed equally

Department of Surgery, University of Melbourne, Austin Hospital, Heidelberg, Australia
}

presence of extra hepatic disease, potential residual liver volume and function as well as the general health of the patient are the main factors that limit the surgical option to approximately $10-25 \%$ of patients $[2,3]$. Advances in systemic therapies have progressively increased the potential for surgical intervention by down staging hepatic metastases in a small subset of patients [4]. Despite successful surgery, the majority of patients develop disease recurrence most frequently in the liver.

Local thermal ablation was developed to increase the therapeutic options for patients with liver metastases $[5,6]$. This involves the application of laser, 
radiofrequency or microwave energy to the tumor. The particular energy in each case is converted into heat that leads to tumor destruction by coagulative necrosis. The aim is to extend the necrosis into a rim of normal tissue parenchyma surrounding the tumor for total tumor destruction [7-9]. When applied as a minimally invasive technique, thermal ablation has a number of potential advantages including significantly lower morbidity, minimal destruction of normal liver tissue and transient changes in liver function enzymes, leading to a lesser regenerative response and the ability for repeated application [10-13].

Early clinical comparisons between resection and thermal ablation suggested that thermal ablation is associated with a less favourable outcome [5]. Results from experimental animal studies however suggest that thermal ablation of metastatic liver tumors is associated with reduced incidence of tumor growth and metastasis compared to resection. Additionally a positive effect on host immune response has been reported following thermal ablation of tumors where the ablated tumor antigens appear to behave like a tumor vaccine [14-16].

This study investigated immune responses in mice with CRC liver metastases following LA of selected tumors. In particular, it focused on changes of Kupffer cells (or tumor infiltrating macrophages; TAMs) and $\mathrm{CD} 3+\mathrm{T}$ cells representing innate and adaptive immunity respectively and on IFN $\gamma$ expression which is associated with Th1 protective immune responses in cancer [17]. The experimental plan was designed to investigate if protective immune responses occur in a scenario reflecting clinical application of LA, where residual micrometastases or tumor at the margins of an ablation site remain after treatment.

\section{Methods}

\section{Animals}

Six to eight week old male CBA mice (Laboratory Animal services, University of Adelaide, South Australia) were used in all experiments. Mice were maintained in standard cages with access to irradiated food and water ad libitum, and exposed to a twelve hour light/dark cycle. All procedures were implemented in accordance with the guidelines of the Austin Health Animal Ethics Committee.

\section{Experimental model of CRC liver metastases}

The primary cell line MoCR was derived from a dimethyl hydrazine (DMH)-induced primary colon carcinoma in the CBA mouse and maintained in vivo by serial passage in the flanks of CBA mice [18]. For passage and experimentation, tumors grown subcutaneously were teased, passed through a filter, treated with EDTA and washed in PBS to make a single cell suspension.
Liver metastases were induced by an intrasplenic injection of $5 \times 10^{4}$ tumor cells prior to splenectomy as reported previously [18]. In this model, liver metastases are fully established by 21 days following tumor induction.

\section{Laser Ablation Treatment}

Twenty-one days after tumor induction animals were used for LA study. Similarly located intra-parenchymal tumors of $7 \mathrm{~mm}$ diameter were chosen for sub-total laser ablation and was performed as described previously [19]. Briefly a Neodymium Yttrium-Aluminium-Garnet (Nd:YAG-wavelength of $1064 \mathrm{~nm}$ ) laser (Dornier medilas fibertom 4100 Medizintechnik $\mathrm{GmbH}$, Munchen) was used. Animals were anaesthetized and a bilateral sub-costal incision was performed to allow full exposure of the liver. A $400 \mu \mathrm{m}$ bare tip optical quartz fibre delivered laser energy, applying 100J of power per tumor (50 seconds at 2 Watts). The treatment parameters were chosen based on our previous extensive studies where the nature and extent of injury including temperature profiles were examined [19-21]. Average tissue temperatures reach $65^{\circ} \mathrm{C}$ adjacent to the fibre site without causing tissue charring. Higher power settings in this animal model generally produce charring. This setting in tumor tissue produces incomplete necrosis that does not extend into the liver. For endpoints other than 0 the treated tumors were marked with special dye (Davidson Tissue Marking System, Bradley Products, Grale Scientific, Melbourne, Australia), the abdomen was closed and animals recovered.

\section{Tissue Sample Collection}

At each endpoint after LA treatment, mice were anesthetized and their liver was excised. The two ablated or sham treated (no activation of the probe) tumors were identified and then immediately dissected from the liver together with surrounding liver tissue. Samples of liver tissue and untreated tumors were also collected. All specimens were fixed in formalin for 48 hours and processed for immunohistochemistry.

\section{Experimental Design}

Three study groups were used: The first study aimed to establish the baseline distribution of $\mathrm{T}$ cells and Kupffer cells in tumor bearing livers and consisted of two groups of mice. The experimental group was induced with metastatic tumor cells 21 days prior to tissue collection and controls consisted of a group of mice from the same cohort but not induced with tumor. The second study investigated temporal changes in the distribution of $\mathrm{T}$ cells, Kupffer cells and IFN $\gamma$ expression, when non tumor bearing animals were treated with TA in the liver tissue and compared to baseline controls (shams: 
liver not treated with TA). The third study investigated temporal changes in the distribution of $\mathrm{T}$ cells, Kupffer cells and IFN $\gamma$ expression in liver and metastatic tumor tissues following TA treatment of two selected tumors. The results were compared to baseline controls (day 21 post tumor induction and day 0 post TA treatment).

\section{Immunohistochemistry}

Formalin fixed paraffin embedded 4- $\mu$ m-thick sections of the tissues were deparaffinized and rehydrated using standard techniques. Endogenous peroxidases were blocked by incubation in 3\% peroxide in methanol for 10 minutes. Antigen retrieval was achieved by incubation in Proteinase $\mathrm{K}$ in a $37^{\circ} \mathrm{C}$ oven for 20 minutes, followed by a cooling down period of 10 minutes at room temperature (RT). Normal goat serum (20\%) was used to block non specific binding. Commercially available primary antibodies used for staining (CD3; rabbit antihuman CD3+ polyclonal A0452, Dakocytomation, Denmark at $0.6 \mu \mathrm{g} / \mathrm{ml}$, IFN $\gamma$; rat anti-mouse IFN $\gamma$ monoclonal 3321-3-1000, Mabtech, Australia, at $1 \mu \mathrm{g} / \mathrm{ml}$, Kupffer cell staining; rat anti mouse F4/80 monoclonal antibody, ATCC no. HB-198, culture supernatant at 1:50 dilution). Negative controls were incubated with the respective non immune antibody isotypes at the same concentration as the primary antibody. Sections were incubated with primary antibodies overnight at $4^{\circ}$ C. Sections treated with the rat antibodies were treated with a rabbit anti-rat linker antibody before treatment with a polymer based detection kit containing goat antirabbit immunoglobulins (IgG) linked to horseradish peroxidase (HRP) (Envision Plus, Dako, Australia). Each incubation step was followed by two five minute washes with PBS $+0.05 \%$ Tween 20. Positive staining was visualized using diaminobenzidine (DAB) as a substrate.

\section{ELISpot assay}

Mouse spleens were collected from LA treated and sham LA treated mice and the spleen cells from each group were pooled. Spleen cells $\left(10^{6}\right.$ per well in $100 \mu \mathrm{L}$ RPMI complete medium) were incubated without stimulation for $18 \mathrm{~h}$ in 96-well plates (MAIPS; Millipore, Australia) precoated with host species anti-murine IFN $\gamma$ (clone R4, American Type Culture Collection, Manassas, VA). Triplicate wells were set up for each condition. After washing wells with PBS, secreted cytokine was detected with biotinylated anti-murine IFN $\gamma$ (MAb XMG.21-biotin; Pharmingen, Australia) followed by extravidin-alkaline phosphatase at $100 \mu \mathrm{g} / \mathrm{mL}$ (Sigma). Spots of activity were detected with a colorimetric alkaline phosphatase kit (Bio-Rad, Hercules, California, USA) and counted using a plate reader (AID GmbH, Germany) with AID ELISpot software Version 3.0. Data are presented as mean spot-forming units (SFU) per million cells \pm standard error of the mean (SEM).

\section{Quantification of CD3+ T cell and Kupffer cell staining}

All sections were examined using a digital microscope system (Coolscope, Nikon Corporation, Chiyokd-ku, Tokyo, Japan). Areas of interest were identified and photomicrographs for each region were captured for enumeration of lymphocytes within (1) tumor-host interface (treated and untreated distant tumors), (2) LA injury front and (3) distant normal liver away from the ablation sites. Images were coded and analyzed using an image analysis program in a blinded manner (Image-Pro Plus Version 4.5.1, Media Cybernetics, USA). Counts were expressed as the number of positive cells per $\mathrm{mm}^{2}$ of tissue. Alternatively positive stained areas were calculated using Image-Pro Plus software and expressed as arbitrary units.

\section{Semi-quantitative analysis of IFN $\gamma$}

Areas of interest were identified using a light microscope (Olympus BH2, Japan) at a magnification of 125x. The entire margin of treated normal liver, tumor host interface of treated/untreated tumor and normal liver tissues were examined. Scoring criteria was used to estimate the amount and intensity of staining seen in each sample. The grading system used was: as: 0: no staining 1: faint staining; 2: small amount or weak staining; 3: moderate staining; 4: abundant or strong staining; 5 : Abundant or very strong staining. Means for each group were determined using the individual scores from each sample.

\section{Statistical assessment}

Statistical analyses were performed using SPSS program (Statistical Package for the Social Sciences ${ }^{\mathrm{TM}}$, version 10, Chicago, Illinois, USA). All data was expressed as the mean \pm standard error of the mean unless otherwise specified. Data was tested for normality using detrended Q-Q plots, descriptive statistics such as skewness and kurtosis and the Kolgomorov-Smironov test prior to statistical analysis. Differences between groups were assessed by non parametric Kruskall Wallis followed by Mann Whitney U tests or parametric ANOVA followed by Tukey post hoc analysis as appropriate. A P value of 0.05 or less was regarded as statistically significant.

\section{Results}

Tumor induces accumulation of CD3+ T cells and Kupffer cells in liver and tumor tissues

The presence of liver metastases increased the concentration of both CD3+ T cells and Kupffer cells in the liver parenchyma as seen in Figure 1 (panels a and $\mathrm{c}$ $\mathrm{CD} 3+$ immunostained sections, panels $\mathrm{b}$ and $\mathrm{d}$ F4/80 immunostained sections. Tumor bearing CD3+ cell count; $85.2 \pm 12.1 \mathrm{cell} / \mathrm{mm}^{2}$ vs. naive $28.3 \pm 2.8 \mathrm{cell} /$ $\mathrm{mm}^{2}, \mathrm{P}<0.002$ and Kupffer cell count; $673.1 \pm 39.6$ cell $/ \mathrm{mm}^{2}$ vs. naive $370.6 \pm 10.6 \mathrm{cell} / \mathrm{mm}^{2}, \mathrm{P}<0.0003$, panels $g$ and $h$ respectively). Accumulation of both cell 


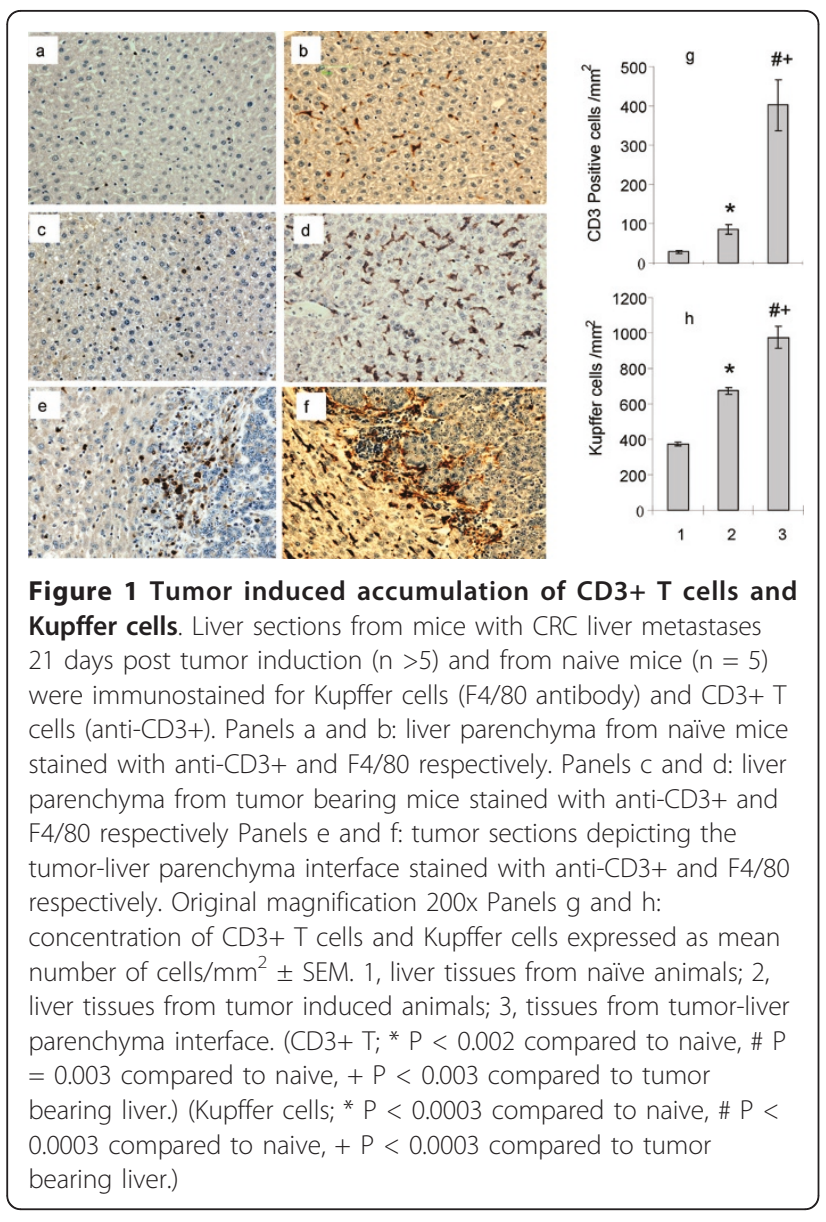

types was observed in the tumor tissues especially at the tumor/host interface and within the vascular lakes (Figure 1 panel e for CD3+ $\mathrm{T}$ cells and $\mathrm{f}$ for Kupffer cells). The concentration of both cell types at the tumor host interface were significantly higher than those in liver parenchyma of naïve animals (Figure 1 panels $g$ and h, $\mathrm{CD} 3+$ cells; $402.2 \pm 64.64 .9 \mathrm{cell} / \mathrm{mm}^{2}$ vs $28.3 \pm 2.8 \mathrm{cell} /$ $\mathrm{mm}^{2}, \mathrm{P}=0.003$ and Kupffer cells: $975.6 \pm 61.9$ vs 370.2 \pm 10.6 cells $/ \mathrm{mm}^{2}, \mathrm{P}<0.0003$ ) and also significantly higher than the concentration in tumor bearing liver parenchyma (Figure 1 panels g and h, CD3+ cells: 402.2 \pm 64.64 .9 vs. $85.2 \pm 12.1 \mathrm{cell} / \mathrm{mm}^{2}, \mathrm{P}<0.003$ and Kupffer cells: $975.6 \pm 61.9$ vs $673.1 \pm 39.6$ cell $/ \mathrm{mm}^{2}, \mathrm{P}<$ $0.0003)$. Therefore, these results show that tumor presence results in significant accumulation of CD3+ T cells and Kupffer cells not only within the tumors but also in the liver parenchyma.

\section{Laser ablation of liver tissue induces local and systemic immune responses}

This study examined local and systemic immunological effects of LA treatment on livers from animals with no tumors. LA treatment resulted in the accumulation of

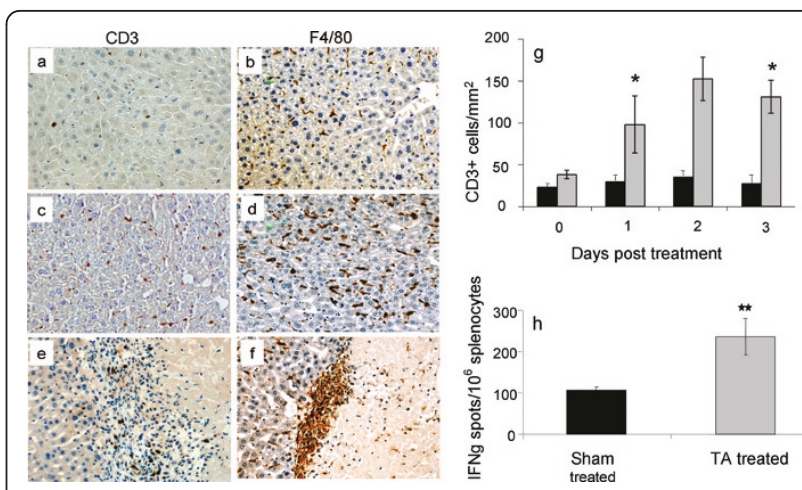

Figure $\mathbf{2}$ Immune responses following LA treatment of liver tissue. Groups of mice $(n>5)$ had LA treatment in the liver and tissue was collected at various time points post ablation as indicated. Control mice had sham LA performed (LA probe was not activated). Panels $a$ and $b$, sham treated liver sections at three days post treatment. Panels $c$ and $d$, liver sections distant from the site of ablation at three days post treatment. Panels e and f, ablated liver sections 3 days post treatment depicting the injury front. Original magnification 200x. Panel g, temporal changes in CD3+ T cells at the injury front following LA treatment expressed as mean number of cells $/ \mathrm{mm}^{2} \pm \mathrm{SEM},{ }^{*} \mathrm{P}<0.05$, compared to control. Panel $\mathrm{h}$, enumeration of IFNy secreting splenocytes at 3 days post liver LA treatment, expressed as mean number of spots/million splenocytes $\pm \mathrm{SEM}^{* *} \mathrm{P}<0.001$, compared to control.

CD3+ T cells and Kupffer cells at the site of injury following treatment compared to sham controls. (Figure 2 panels $\mathrm{a}$ and $\mathrm{e}$ for $\mathrm{CD} 3+$ cells panels $\mathrm{b}$ and $\mathrm{f}$ for Kupffer cells). $\mathrm{CD} 3+\mathrm{T}$ cell accumulation at the injury site persisted over the next three days with the peak occurring on day 2 following LA. (Figure 2g CD3+ increase compared to sham treated liver. P values: Immediate: 0.068; day 1: 0.046; day 2: 0.053; day 3: 0.034, Mann Whitney U tests). In an earlier study, we demonstrated that Kupffer cell accumulation displayed a biphasic increase, with an initial peak followed by a decrease over the next two days, and then another peak at days three to five [19]. In this respect the Kupffer cell kinetics were different to those of CD3+ T cells, where a single peak was observed in the current study. Increases in both Kupffer and CD3+ T cell concentration after ablation were also observed within the distant uninjured parenchyma (Figure $2 \mathrm{c}$ and figure $2 \mathrm{~d}$ respectively and Additional file 1, Figure S1). LA treatment of the liver also induced a systemic immune response. Significantly greater number of splenocytes from treated animals secreted IFN $\gamma$ at three days after LA treatment compared to controls (Figure $2 \mathrm{~h} ; 235 \pm 43.5$ vs $106.3 \pm 8.0$ IFN $\gamma$ secreting cells per million splenocytes respectively, $\mathrm{P}<$ 0.001). These results represent in-vivo stimulation as the splenocytes were not further stimulated during the ELISpot assay, indicating that LA treatment induces immune responses not only locally but also systemically even in the absence of tumor. 
Laser ablation of selected tumors induces concentration and distribution changes of $\mathrm{CD} 3+\mathrm{T}$ cells in tumor and liver tissues

Changes in concentration and distribution of CD3+ T cells in tumor and liver tissues (Figure 3a) following LA of two tumors were investigated at various time points post treatment and compared to sham treated mice. Sham treatment did not significantly change the frequency or distribution of CD3 $+\mathrm{T}$ cells in any of the liver tissues compared to untreated animals. Furthermore there was no significant temporal change during the different time points post sham treatment. In contrast, LA treatment produced an immediate increase in $\mathrm{CD} 3+\mathrm{T}$ cell concentration in the liver parenchyma above the sham values (Figure 3e compared to Figure 3b). Immediate increases were also seen at the tumor host interface of ablated and distant tumors, at the ablation injury front and within vascular lakes of ablated and distant tumors. These increases persisted at high levels compared to shams at all time points (Figure 3 panels $\mathrm{f}$-h for distant tumors and panels $\mathrm{i}-\mathrm{l}$ for ablated tumors). CD3+ T cells were not uniformly distributed however, with patches of very high numbers observed at the injury front (Figure 3 panels $i$ and $j$ ) and at the tumor host interface (Figure 3 panels $\mathrm{k}$ and $\mathrm{l}$ ) while in neighbouring regions accumulation was a lot less prevalent. Similarly some vascular lakes within distant tumors were observed to be densely populated with $\mathrm{CD} 3+\mathrm{T}$ cells while others were not. In general the most consistent accumulation was observed at the tumor-host interface of both ablated and distant tumors.

Temporal changes in CD3 $+\mathrm{T}$ cells at the tumor-host interface of ablated and distant tumors were biphasic with an initial rise followed by a small decrease and then a second higher peak occurring between day 3 to 7 for both the ablated and distant tumor-host interface (Figure 4). Infiltration of CD3+ T cells at the tumor host interface of LA treated tumors was increased at all time points post treatment compared to sham operated tumor-host interface ( $\mathrm{P}$ values: $0.050 ; 0.061 ; 0.066$; 0.050; 0.060 and 0.034; for time points $0,1,2,3,5$ and 7 days respectively; Figure 4a. grey bars). Similarly infiltration of CD3 $+\mathrm{T}$ cells increased at tumor-host interface in distant tumors of LA treated animals compared to equivalent tissues of sham treated animals ( $P$ values: $0.119 ; 0.098 ; 0.026 ; 0.184 ; 0.000$ and 0.003 ; for time
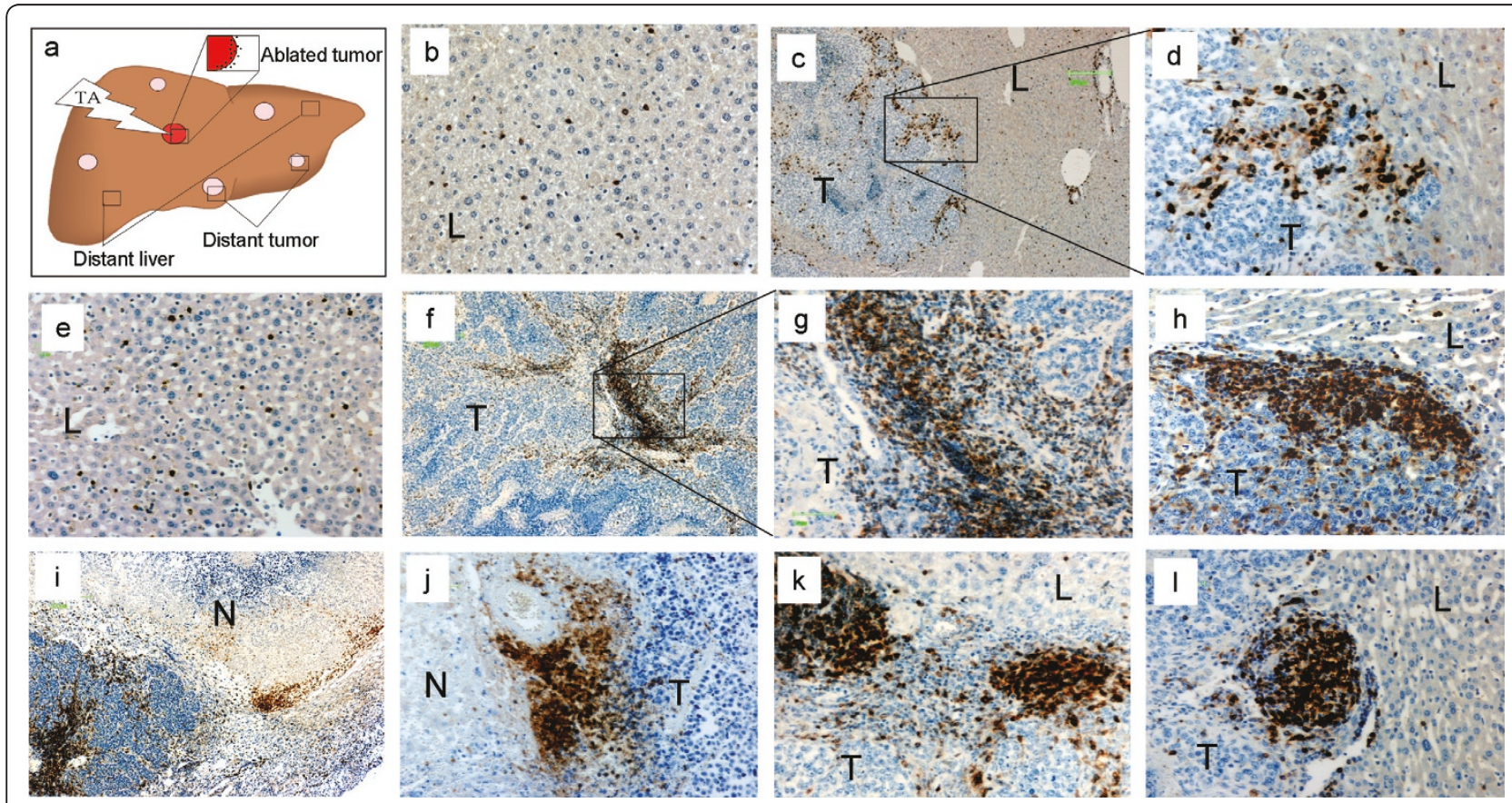

Figure 3 Changes in CD3+ T cell frequency and distribution following LA treatment of selected liver metastases. Groups of mice ( $\mathrm{n}>5$ ) had two tumors LA treated and tissues were collected at various time points post ablation from areas indicated in the diagram of panel a. Control mice had sham LA performed (LA probe was not activated). Panels b-d are CD3+ stained tissues from control animals; $b$ liver parenchyma, c tumor host interface and $d$ an enlarged section of $c$ as shown in the rectangle. Panel e depicts a section of liver parenchyma from an LA treated animal immediately following ablation. Panels $\mathrm{f}-\mathrm{I}$ are CD3+ stained tumor sections from LA treated animals collected at day 2 post treatment. Panels $f$ and $g$ depict CD3+ staining of a vascular lake in a distant tumor; $g$ is an enlarged section of panel $f$ as shown in the rectangle. Panel h depicts a section of distant tumor host interface Panels $\mathrm{i}$ and $\mathrm{j}$ depict sections of the ablated tumor injury front. Panels $\mathrm{k}$ and $\mathrm{I}$ depict sections of the ablated tumor host interface. Panels c, f and i original magnification 50x, all other panels original magnification 200x. L, liver; $T$, tumor; $N$, necrotic tissue within the injury front. 


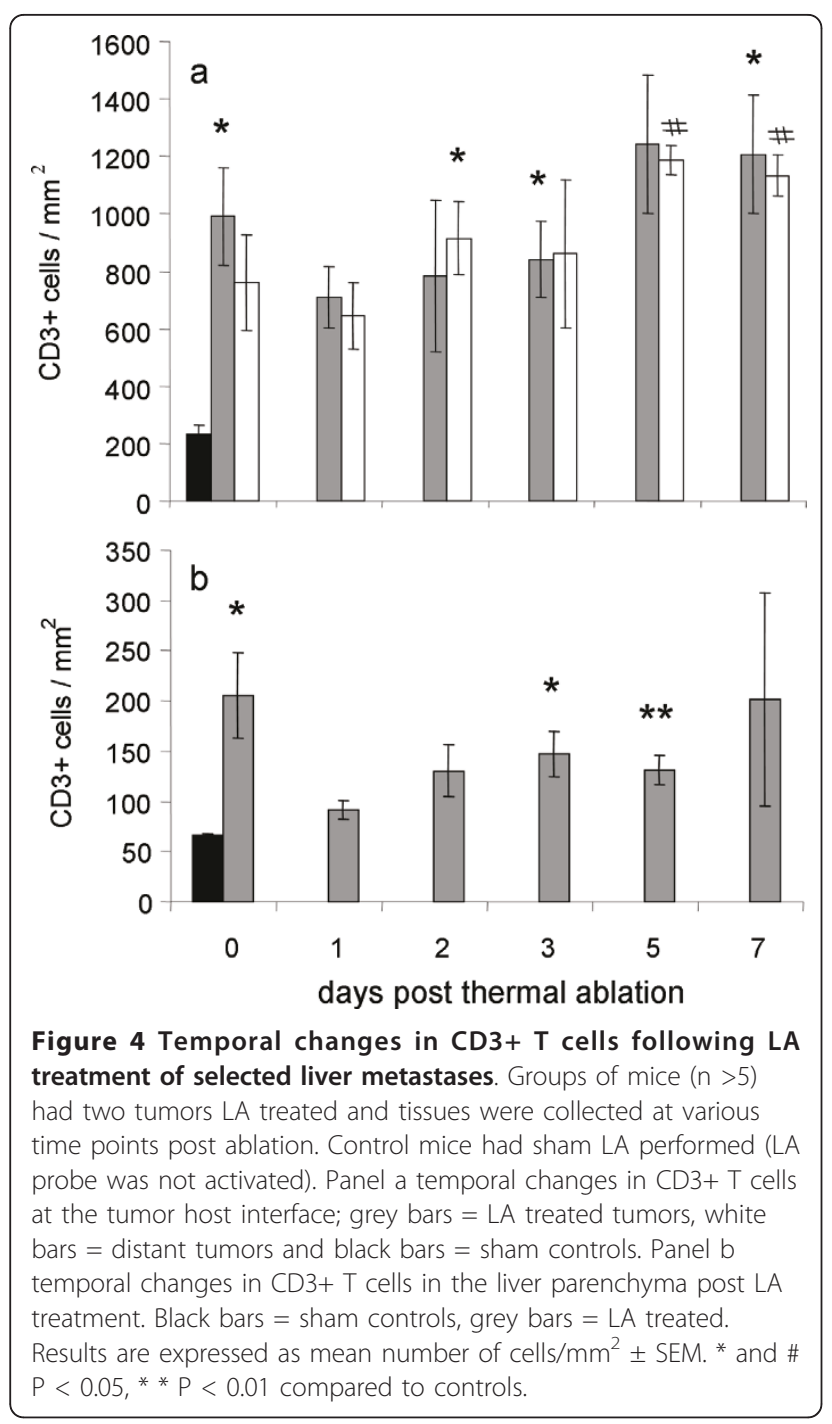

points $0,1,2,3,5$ and 7 respectively; Figure 4a. white bars).

Temporal biphasic changes of CD3+ $\mathrm{T}$ cell numbers were seen within the liver parenchyma distant from the ablation sites Figure 4b. These changes showed an immediate peak which was then followed by a second peak, with significant differences seen in $\mathrm{CD} 3+\mathrm{T}$ cell numbers between the treated and sham groups ( $P$ values: Immediate: 0.050, Day 1: 0.086; Day 2: 0.086; Day 3: 0.043; Day 5: 0.008; Day 7: 0.433, t tests) after LA treatment, suggesting systemic trafficking of these cells.

\section{Laser ablation of specific tumors induces increased IFN $\gamma$ expression in tumor tissues}

Tissues were collected as described in Figure $3 \mathrm{a}$ and immunostaining for IFN $\gamma$ was performed. The expression of IFN $\gamma$ appears diffuse and generalised rather than localised within cells and therefore a scoring technique was used. Immediately following treatment, there was increase in staining at the tumor host interface when compared to sham treatment (Figure 5 a and 5b). Following LA treatment, IFN $\gamma$ expression over time displayed a biphasic pattern (Figure 5c) with an initial peak at day 1 followed by a second peak between days 3 and 7 similar to that seen for CD3+ $\mathrm{T}$ cells (P values Day 0: 0.171, Day 1: 0.022; Day 2: 0.703; Day 3: 0.210; Day 5: 0.044; Day 7: 0.040, compared to sham treated, Mann Whitney $\mathrm{U}$ tests). IFN $\gamma$ expression also increased at distant tumor host interface; however the increases did not reach significance levels (result not shown).

\section{Changes in concentration and distribution of Kupffer cells in tumor and liver tissues following laser ablation of tumors}

In a previous study we have shown that Kupffer cell numbers significantly reduced at site of the tumor ablation injury during the first two days following treatment and then significantly increased, peaking on day 3 but remaining significantly elevated compared to untreated control for all further time points tested [19]. In the present study we examined temporal changes of $\mathrm{KC}$ at the margins of untreated tumors distant to the ablation site. There was no significant difference between sham ablated and ablated groups (Figure 6a), however significant increases were seen in the liver parenchyma distant to ablation site in the LA treated compared to sham treated animals (Figure $6 \mathrm{~b}$ ), suggesting systemic trafficking of these cells.

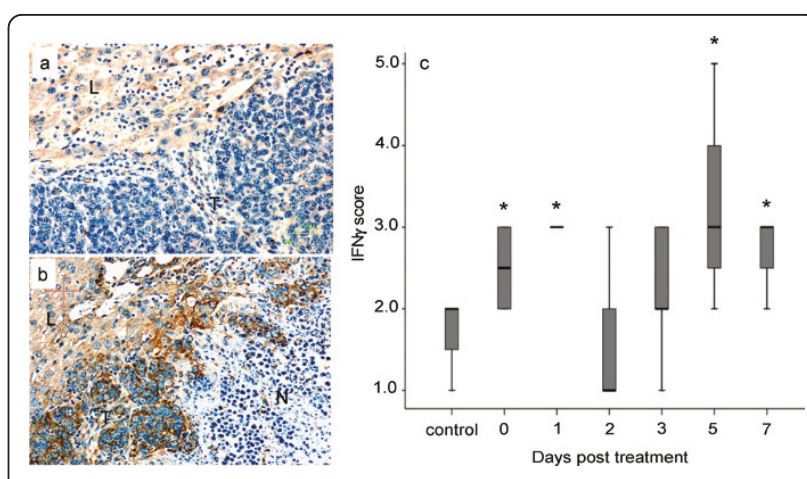

Figure 5 Temporal changes in IFN $\gamma$ expression following LA treatment of selected liver metastases. Groups of mice $(n>5)$ had two tumors LA treated and tissues were collected at various time points post ablation. Control mice had sham TA performed (LA probe was not activated). Panels $a$ and $b$ tumor sections from control (sham ablated) and LA treated animals at day 5 post treatment respectively, stained with rat anti IFN $\gamma$ monoclonal antibody. L; liver, $\mathrm{T}$; tumor, $\mathrm{N}$; necrotic area at the LA injury front. Panel $c$; temporal changes in IFN $\gamma$ expression at the tumor host interface and injury front expressed as mean intensity score \pm SEM. * $\mathrm{P}<0.05$ compared to sham control. 


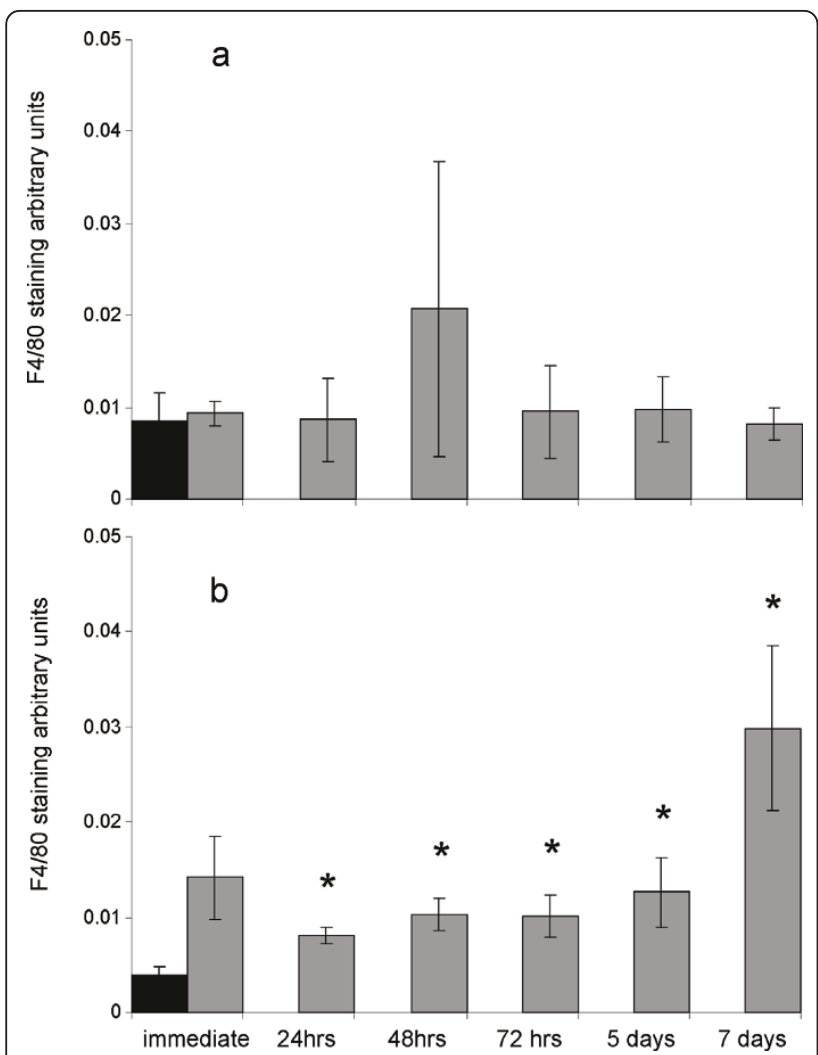

Figure 6 Temporal changes in Kupffer cells following LA treatment of selected liver metastases. Groups of mice $(n>5)$ had two tumors LA treated and tissues were collected at various time points post ablation. Control mice had sham LA performed (LA probe was not activated). F4/80 positive areas were calculated using image pro plus software. Values are expressed as mean arbitrary units \pm SEM. Panel a; black bar, Kupffer cells at the tumor host interface distant from sham treated tumors; grey bars, Kupffer cells at the tumor host interface distant from ablated tumors. $\mathrm{P}>0.05$ compared to sham control at all time points. Panel b; black bar, F4/ 80 staining in liver tissue of sham treated mice; grey bars, F4/80 staining in liver tissue distant from ablated tumor site. ${ }^{*} \mathrm{P}<0.05$ compared to sham control.

\section{Discussion}

Thermal ablation has evolved as a significant minimally invasive treatment for unresectable CRC liver metastases as well as an adjunct to liver resection [22]. Accumulating evidence suggests that in situ tumor destruction by thermal ablation may also stimulate local and systemic anti-tumor immunity, with the potential to eliminate not only treated tumors, but also residual micrometastases which normally give rise to tumor recurrence; reviewed by Gravante et al [16]. In previous studies we have shown that LA destroys tumor or liver tissue by generating immediate focal necrosis followed by a marked inflammatory response and progressive increase in the area of injury [8]. We have also demonstrated significant accumulation of Kupffer cells and increased expression of HSP70 at the injury front persisting for a number of days following LA treatment [19]. In the present study we demonstrate $\mathrm{T}$-cell accumulation not only at the LA injury site, but also within liver parenchyma and tumor/host interface of both ablated tumors and residual tumors distant from the site of ablation. In contrast Kupffer cells only accumulated in ablated tumors and the liver parenchyma but not in distant tumors. IFN $\gamma$ expression increased significantly in ablated tumors and showed an increasing trend in tumors distant from the ablation site. In addition significantly more splenocytes from liver ablated animals secreted IFN $\gamma$ compared to controls.

In clinical studies, thermal ablation of tumors has been shown to result in early systemic inflammation, the induction and systemic trafficking of specific anti-tumor $\mathrm{T}$-cell responses involving $\mathrm{CD} 4+$ and $\mathrm{CD} 8+\mathrm{T}$ cells $[23,24]$ and a generalized adjuvant effect that also involved the activation of natural killer cells [25,26].

In experimental studies, total tumor destruction by thermal ablation protected animals from further tumor challenge [27] while partial tumor removal by thermal ablation resulted in significant residual tumor inhibition and systemic tumor specific CD4+ and CD8+ T-cell induction compared to resection [28]. The mechanisms by which thermal ablation activates the immune system are not clear at this stage, accumulating evidence however suggest the involvement of both the innate and the adaptive immune systems and their cytokines [16].

Our results indicate that presence of tumor alters the molecular environment of the liver in ways that attract accumulation of immune cells (CD3 T cells and Kupffer cells). Infiltration of Kupffer cells (or TAMs) into tumors has been reported in many other studies. Macrophages activated in the classical pathway (M1) favoring a Th1 immune response (IFN $\gamma, \mathrm{NO}, \mathrm{TNF} \alpha$, IL-1 and IL12 secretion) are associated with tumoricidal functions. Macrophages infiltrating the tumor microenvironment however are usually activated along the M2 pathway promoting Th2 type immune responses [29] and tumor progression by releasing proangiogenic cytokines and growth factors (VEGF, IL-8, b-FGF) and matrix metalloproteases (MMPs) that digest the tumor basement membrane, facilitating tumor metastasis [30].

Infiltration and accumulation of CD3+ T cells within colorectal and other tumors has also been reported in several other studies. The significance of this infiltration is controversial. Early studies associate it with a favourable outcome [31,32]. More recent studies however indicate that $\mathrm{T}$ cell infiltration in solid tumors are at best ineffectual in controlling tumor growth and most often contribute to tumor progression by enabling the neutralisation of immune responses [33]. The tumor microenvironment subverts the immune response in a variety of 
ways to support tumor growth. All CD3+ T cell subtypes have been shown to be capable of promoting tumor progression, either through altered cytokine production such as IL-1, IL-4, TGF- $\beta$ and IL-10 [34-36] or through cell-cell contact after being converted into FoxP3 regulatory $\mathrm{T}$ cells by the influence of tumor stroma derived immunosuppressive factors such as PGE2, TGF- $\beta$ or IDO by-products $[37,38]$. Thermal ablation studies suggest that the treatment induces protective Th1 immune responses to counteract the immunosuppressive tumor microenvironment. Antigens from thermally ablated hepatocellular carcinoma induced superior stimulation of in vitro immune responses than untreated tumor antigens [39] and vaccination with antigens from thermally treated tumors prior to thermal ablation enhanced the treatment outcome [40]. This is most likely achieved by the upregulation of HSP proteins including HSP70 that we and others have shown to occur after LA treatment [19]. HSP70, a stress induced molecular chaperone, has a dual role in inducing a Th1 anti-tumor response. HSP70 acts as a general adjuvant, signaling through toll-like receptor 4 (TLR-4) [41] resulting in the maturation and activation of dendritic cells (DCs). Maturation of DCs is required to efficiently present antigenic peptides for protective immune responses. HSP70 also forms complexes with all the tumor antigens so it also induces tumor specific immune responses by delivering specific antigens to DCs [42]. Maturation of dendritic cells and efficient antigen presentation results in a Th1 immune response capable of overcoming the tumor immunosuppressive environment. It was shown that a Th1 response and upregulation of IFN $\gamma$ is required for the prevention of tumor establishment or the elimination of already established tumors [17]. The presence of Th1 activated T cells is an independent prognostic marker for patient survival [43].

Upregulation of the Th1 pathway cytokines IL-12 and/ or IFN $\gamma$ within the tumor resulted in tumor killing [44] and directly inhibited tumor angiogenesis [45]. In the current study we demonstrated local and systemic upregulation of IFN $\gamma$ and the accumulation of $\mathrm{CD} 3+\mathrm{T}$ cells at the site of LA injury and at distant tumors. These findings suggest that LA treatment induces a Th1 immune response. Retention of CD3+ cells at the site of injury could be due to the presence of antigen presenting cells activated by HSP70 and displaying antigens from necrotic cells after LA treatment. While both Kupffer cells and CD3+ T accumulated at the tumor host interface and the injury site of the ablated tumor, only $\mathrm{CD} 3+\mathrm{T}$ cells showed significant accumulation at the tumor host interface of distant tumors. This finding implies that a large proportion of CD3+ cells must recognise tumor specific signals, whereas KCs respond to a general inflammation response and specifically accumulate in the ablated tissues. Accumulation of CD3 $+\mathrm{T}$ cells within tumor margins of untreated tumors following thermal ablation treatment have also been reported in other studies using different tumor models $[14,27]$.

In addition to local upregulation of IFN $\gamma$, significantly more splenocytes in LA treated animals produced IFN $\gamma$ compared to sham treated animals indicating induction of a systemic Th1 immune response. IFN $\gamma$ is produced by activated $T$ cells and other cells of the immune system such as NK cells. The temporal kinetic pattern of IFN $\gamma$ expression in this study was similar to that of CD3 + cell infiltration following LA treatment. This finding suggests that the infiltrating CD3+ $\mathrm{T}$ cells would also be activated along the Th1 pathway and may provide an effective mechanism for control of CRC liver metastases.

\section{Conclusions}

We have shown LA treatment induces significant innate and adaptive immune responses, including IFN $\gamma$ upregulation locally and systemically, indicating these responses to be Th1 and therefore tumor inhibiting. The accumulation of $\mathrm{CD} 3+\mathrm{T}$ cells and the increase of IFN $\gamma$ in distant unablated tumors suggest that the response could be beneficial in suppressing outgrowth of residual micrometastases in the clinic. Future work will identify the composition and activation status of the CD3+ T cell population after LA therapy and will validate their protective roles as their modulation may further enhance treatment outcomes.

\section{Additional material}

\begin{abstract}
Additional file 1: Figure S1: Temporal changes in CD3+ T cells and Kupffer cells in the liver parenchyma distant from injury sites following liver LA treatment. Groups of mice $(n>5)$ had LA treatment in the liver and tissue was collected at various time points post ablation as indicated. Control mice had sham LA performed (LA probe was not activated), black bars = sham ablated liver, grey bars = ablated liver. Panels a, CD3+ T cells were counted from paraffin fixed liver tissue sections stained with anti-CD3+ antibody and expressed as mean number of cells $/ \mathrm{mm}^{2} \pm \mathrm{SEM},{ }^{*} \mathrm{P}<0.05$ respectively. Panel $\mathrm{b}$, Kupffer cells were detected with F4/80 antibody staining. Positive areas were calculated using image pro plus software. Values are expressed as mean arbitrary units \pm SEM. * $P<0.05$, compared to sham controls.
\end{abstract}

\section{Acknowledgements}

This work was supported by the Cancer Council of Victoria and Austin Health Medical Research Foundation.

\section{Authors' contributions}

WXL carried out tissue immunostaining, ELISPOT assays, data collection, data analysis and and helped to draft the manuscript. TF participated in the study design, ELISPOT assays, data collection and data analysis and wrote the manuscript. CM-W contributed to tissue collection, performed statistical data analysis and edited the manuscript. MN participated in the study design, 
performed the ablations and collected tissues. VM contributed to the study design, performed some of the ablations and contributed to data analysis. LN contributed to immunostaining and data collection. CC contributed to the study design and critically revised the manuscript. All authors read and approved the final manuscript.

\section{Competing interests}

The authors declare that they have no competing interests.

Received: 17 September 2010 Accepted: 29 May 2011

Published: 29 May 2011

\section{References}

1. Landis SH, Murray T, Bolden S, Wingo PA: Cancer statistics, 1999. CA Cancer J Clin 1999, 49(1):8-31, 31.

2. Cromheecke M, de Jong KP, Hoekstra HJ: Current treatment for colorectal cancer metastatic to the liver. Eur J Surg Oncol 1999, 25(5):451-463.

3. Adam R, Avisar E, Ariche A, Giachetti S, Azoulay D, Castaing D, Kunstlinger F, Levi F, Bismuth F: Five-year survival following hepatic resection after neoadjuvant therapy for nonresectable colorectal. Ann Surg Oncol 2001, 8(4):347-353.

4. Ruers T, Bleichrodt RP: Treatment of liver metastases, an update on the possibilities and results. Eur J Cancer 2002, 38(7):1023-1033.

5. Abdalla EK, Vauthey JN, Ellis LM, Ellis V, Pollock R, Broglio KR, Hess K, Curley SA: Recurrence and outcomes following hepatic resection, radiofrequency ablation, and combined resection/ablation for colorectal liver metastases. Ann Surg 2004, 239(6):818-825, discussion 825-817.

6. Iannitti DA, Martin RC, Simon CJ, Hope WW, Newcomb WL, McMasters KM Dupuy D: Hepatic tumor ablation with clustered microwave antennae: the US Phase II Trial. HPB (Oxford) 2007, 9(2):120-124.

7. Nikfarjam M, Muralidharan V, Malcontenti-Wilson C, Christophi C: Progressive microvascular injury in liver and colorectal liver metastases following laser induced focal hyperthermia therapy. Lasers Surg Med 2005, 37(1):64-73.

8. Christophi C, Winkworth A, Muralihdaran V, Evans P: The treatment of malignancy by hyperthermia. Surgical Oncology 1998, 7(1-2):83-90.

9. Gravante G, Ong S, Metcalfe M, Strickland A, Dennison A, Lloyd D: Hepatic microwave ablation: a review of the histological changes following thermal damage. Liver international 2008, 28(7):911-921.

10. Solbiati L, lerace T, Tonolini M, Osti V, Cova L: Radiofrequency thermal ablation of hepatic metastases. Eur J Ultrasound 2001, 13(2):149-158.

11. Vogl TJ, Straub R, Zangos S, Mack MG, Eichler K: MR-guided laser-induced thermotherapy (LITT) of liver tumours: experimental and clinical data. Int J Hyperthermia 2004, 20(7):713-724.

12. Berber $E$, Siperstein AE: Perioperative outcome after laparoscopic radiofrequency ablation of liver tumors: an analysis of 521 cases. Surgical endoscopy 2007, 21(4):613.

13. Dobbins C, Brennan C, Wemyss-Holden S, Cockburn J, Maddern G: Bimodal electric tissue ablation-long term studies of morbidity and pathological change. The Journal of surgical research 2008, 148(2):251-259.

14. Isbert C, Ritz JP, Roggan A, Schuppan D, Ruhl M, Buhr HJ, Germer CT: Enhancement of the immune response to residual intrahepatic tumor tissue by laser-induced thermotherapy (LITT) compared to hepatic resection. Lasers Surg Med 2004, 35(4):284-292.

15. Hu Z, Yang XY, Liu Y, Sankin GN, Pua EC, Morse MA, Lyerly HK, Clay TM, Zhong P: Investigation of HIFU-induced anti-tumor immunity in a murine tumor model. J Transl Med 2007, 5:34

16. Gravante G, Sconocchia G, Ong S, Dennison A, Lloyd D: Immunoregulatory effects of liver ablation therapies for the treatment of primary and metastatic liver malignancies. Liver international 2009, 29(1):18.

17. Ikeda $H$, Old L, Schreiber R: The roles of IFN gamma in protection against tumor development and cancer immunoediting. Cytokine \& growth factor reviews 2002, 13(2):95.

18. Kuruppu D, Christophi C, Bertram JF, O'Brien PE: Characterization of an animal model of hepatic metastasis. J Gastroenterol Hepatol 1996, 11(1):26-32

19. Nikfarjam M, Muralidharan V, Su K, Malcontenti-Wilson C, Christophi C: Patterns of heat shock protein (HSP70) expression and Kupffer cell activity following thermal ablation of liver and colorectal liver metastases. Int J Hyperthermia 2005, 21(4):319-332.
20. Muralidharan V, Nikfarjam M, Malcontenti-Wilson C, Christophi C: Effect of interstitial laser hyperthermia in a murine model of colorectal liver metastases: scanning electron microscopic study. World J Surg 2004, 28(1):33-37.

21. Nikfarjam M, Muralidharan V, Malcontenti-Wilson C, Christophi C: The apoptotic response of liver and colorectal liver metastases to focal hyperthermic injury. Anticancer Res 2005, 25(2B):1413-1419.

22. Clasen S, Boss A, Schmidt D, Schraml C, Fritz J, Schick F, Claussen C, Pereira P: MR-guided radiofrequency ablation in a 0.2-T open MR system: technical success and technique effectiveness in 100 liver tumors. Journal of magnetic resonance imaging 2007, 26(4):1043.

23. Hansler J, Wissniowski TT, Schuppan D, Witte A, Bernatik T, Hahn EG, Strobel D: Activation and dramatically increased cytolytic activity of tumor specific $T$ lymphocytes after radio-frequency ablation in patients with hepatocellular carcinoma and colorectal liver metastases. World J Gastroenterol 2006, 12(23):3716-3721.

24. Napoletano C, Taurino F, Biffoni M, De Majo A, Coscarella G, Bellati F, Rahimi H, Pauselli S, Pellicciotta I, Burchell J, Gaspari L, Ercoli L, Rossi P, Rughetti A: RFA strongly modulates the immune system and anti-tumor immune responses in metastatic liver patients. International journal of oncology 2008, 32(2):481

25. Zerbini A, Pilli M, Penna A, Pelosi G, Schianchi C, Molinari A, Schivazappa S, Zibera C, Fagnoni F, Ferrari C, Missale G: Radiofrequency thermal ablation of hepatocellular carcinoma liver nodules can activate and enhance tumor-specific T-cell responses. Cancer research 2006, 66(2):1139.

26. Zerbini A, Pilli M, Laccabue D, Pelosi G, Molinari A, Negri E, Cerioni S, Fagnoni F, Soliani P, Ferrari C, Missale G: Radiofrequency thermal ablation for hepatocellular carcinoma stimulates autologous NK-cell response. Gastroenterology 2010, 138(5):1931.

27. Ivarsson K, Myllymäki L, Jansner K, Stenram U, Tranberg KG: Resistance to tumour challenge after tumour laser thermotherapy is associated with a cellular immune response. British Journal of Cancer 2005, 93(4):435-440.

28. Dromi SA, Walsh MP, Herby S, Traughber B, Xie JW, Sharma KV, Sekhar KP, Luk A, Liewehr DJ, Dreher MR, Fry TJ, Wood BJ: Radiofrequency Ablation Induces Antigen-presenting Cell Infiltration and Amplification of Weak Tumor-induced Immunity. Radiology 2009, 251(1):58-66

29. Allavena P, Sica A, Garlanda C, Mantovani A: The Yin-Yang of tumorassociated macrophages in neoplastic progression and immune surveillance. Immunological reviews 2008, 222:155-161.

30. Hagemann T, Robinson S, Schulz M, TrÃ $1 / 4$ mper L, Balkwill F, Binder C: Enhanced invasiveness of breast cancer cell lines upon co-cultivation with macrophages is due to TNF-alpha dependent up-regulation of matrix metalloproteases. Carcinogenesis 2004, 25(8):1543.

31. Menon AG, Janssen CM, Rhijn CM, Morreau H, Putter $H$, Tollenaar $R$, van de Velde CJH, Fleuren GJ, Kuppen PJK: Immune system and prognosis in colorectal cancer: a detailed immunohistochemical analysis. Laboratory Investigation 2004, 84(4):493-501.

32. Ohtani H: Focus on TILs: prognostic significance of tumor infiltrating lymphocytes in human colorectal cancer. Cancer immunity 2007, 7:4

33. Ruffell B, DeNardo D, Affara N, Coussens L: Lymphocytes in cancer development: polarization towards pro-tumor immunity. Cytokine \& growth factor reviews 2010, 21(1):3.

34. Aspord C, Pedroza-Gonzalez A, Gallegos M, Tindle S, Burton E, Su D, Marches F, Banchereau J, Palucka AK: Breast cancer instructs dendritic cells to prime interleukin 13-secreting CD4+ T cells that facilitate tumor development. The Journal of experimental medicine 2007, 204(5):1037.

35. DeNardo D, Barreto J, Andreu P, Vasquez L, Tawfik D, Kolhatkar N, Coussens L: CD4(+) T cells regulate pulmonary metastasis of mammary carcinomas by enhancing protumor properties of macrophages. Cancer cell 2009, 16(2):91-102

36. Jarnicki A, Lysaght J, Todryk S, Mills KHG: Suppression of antitumor immunity by IL-10 and TGF-beta-producing T cells infiltrating the growing tumor: influence of tumor environment on the induction of CD4+ and CD8+ regulatory T cells. The journal of immunology 2006, 177(2):896-904.

37. Sharma S, Yang SC, Zhu L, Reckamp K, Gardner B, Baratelli F, Huang M, Batra R, Dubinett S: Tumor cyclooxygenase-2/prostaglandin E2dependent promotion of FOXP3 expression and CD4+ CD25+ T regulatory cell activities in lung cancer. Cancer research 2005, 65(12):5211.

38. Curti A, Pandolfi S, Valzasina B, Aluigi M, Isidori A, Ferri E, Salvestrini V, Bonanno G, Rutella S, Durelli I, Horenstein A, Fiore F, Massaia M, 
Colombo M, Baccarani M, Lemoli R: Modulation of tryptophan catabolism by human leukemic cells results in the conversion of CD25- into CD25+ T regulatory cells. Blood 2007, 109(7):2871-2877.

39. Zerbini A, Pilli M, Fagnoni F, Pelosi G, Pizzi M, Schivazappa S, Laccabue D, Cavallo C, Schianchi C, Ferrari C, Missale G: Increased immunostimulatory activity conferred to antigen-presenting cells by exposure to antigen extract from hepatocellular carcinoma after radiofrequency thermal ablation. Journal of immunotherapy 2008, 31(3):271-282.

40. Liu Q, Zhai B, Yang W, Yu LX, Dong W, He YQ, Chen L, Tang L, Lin Y, Huang DD, Wu HP, Wu MC, Yan HX, Wang HY: Abrogation of Local Cancer Recurrence After Radiofrequency Ablation by Dendritic Cell-based Hyperthermic Tumor Vaccine. Mol Ther 2009.

41. Chen T, Guo J, Han C, Yang M, Cao X: Heat shock protein 70, released from heat-stressed tumor cells, initiates antitumor immunity by inducing tumor cell chemokine production and activating dendritic cells via TLR4 pathway. The journal of immunology 2009, 182(3):1449.

42. Castelli C, Rivoltini L, Rini F, Belli F, Testori A, Maio M, Mazzaferro V, Coppa J, Srivastava P, Parmiani G: Heat shock proteins: biological functions and clinical application as personalized vaccines for human cancer. Cancer immunology and immunotherapy 2004, 53(3):227.

43. Galon J, Costes A, Sanchez-Cabo F, Kirilovsky A, Mlecnik B, Lagorce-Pages C, Tosolini M, Camus M, Berger A, Wind P, Zinzindohoue F, Bruneval P, Cugnenc P-H, Trajanoski Z, Fridman W-H, Pages F: Type, density, and location of immune cells within human colorectal tumors predict clinical outcome. Science 2006, 313(5795):1960-1964.

44. Kilinc M, Rowswell-Turner R, Gu T, Virtuoso L, Egilmez N: Activated CD8+ Teffector/memory cells eliminate CD4+ CD25+ Foxp3+ T-suppressor cells from tumors via FasL mediated apoptosis. The journal of immunology 2009, 183(12):7656-7660

45. Sorensen E, Gerber S, Frelinger J, Lord E: IL-12 suppresses vascular endothelial growth factor receptor 3 expression on tumor vessels by two distinct IFN-gamma-dependent mechanisms. The journal of immunology 2010, 184(4):1858.

doi:10.1186/1479-5876-9-83

Cite this article as: Lin et al: Induction of Th1 Immune responses following laser ablation in a murine model of colorectal liver metastases. Journal of Translational Medicine 2011 9:83.

\section{Submit your next manuscript to BioMed Central and take full advantage of:}

- Convenient online submission

- Thorough peer review

- No space constraints or color figure charges

- Immediate publication on acceptance

- Inclusion in PubMed, CAS, Scopus and Google Scholar

- Research which is freely available for redistribution

Submit your manuscript at www.biomedcentral.com/submit
Biomed Central 